\title{
Titanium borides deposited by chemical vapor deposition thermodynamic calculation and experiments
}

\author{
M. NADAL, T. GRENET and F. TEYSSANDIER
}

Institut de Science et de Génie des Matériaux et Procédés, Université de Perpignan, 52 avenue de Villeneuve, 66860 Perpignan cedex, France

\begin{abstract}
The deposition conditions of titanium diboride and titanium monoboride were calculated under the thermodynamic equilibrium assumption and experimentally checked. The theoretical deposition diagram was calculated by the SOLGASMIX program. All the gaseous and condensed species were taken into account. The initial gas mixture was composed of titanium tetrachloride, boron trichloride and hydrogen. The calculated diagram shows that low partial pressures of boron trichloride and titanium tetrachloride are both required in order to be able to deposit titanium monoboride. The deposition experiments were carried out at atmospheric pressure in a cold wall reactor. The substrates were either molybdenum or molybdenum coated by TiC. They were inductively heated by a RF coil to the deposition temperature $(1473 \mathrm{~K})$. Special devices were used to reach the low partial pressures of titanium tetrachloride and boron trichloride necessary to deposit titanium monoboride. The nature of the coatings were determined by X-ray diffraction and EPMA-WDS. Titanium diboride as well as titanium monoboride was obtained by varying the composition of the initial gas phase. The hardness of $\mathrm{TiB}_{2}$ was measured by ultra low load indentation.
\end{abstract}

\section{1-Introduction}

Metal borides have been investigated for applications where refractory properties are required. Among them titanium diboride $\left(\mathrm{TiB}_{2}\right)$ has been the most studied for various applications such as diffusion barrier [1-3] resistance coating against oxidation [4] or for its electrical properties [5]. Mainly prepared by conventional chemical vapor deposition it has also been obtained by laser enhanced CVD [6] or by a modified hot wire method [7]. Most of the papers dealing with conventional chemical vapor deposition are concerned with the deposition rate, the morphology and/or the $X$-ray diffraction characterization of the deposits [8-14]. The preferred orientation [15] as well as the interaction with substrates [16] and mainly metallic substrates [17-18] have also been investigated.

Titanium diboride is easily obtained by $\mathrm{CVD}$ from a $\mathrm{TiCl}_{4}-\mathrm{H}_{2}$ and $\mathrm{BCl}_{3}$ or $\mathrm{B}_{2} \mathrm{H}_{6}$ gas mixture from 700 to $2150^{\circ} \mathrm{C}$. Two other compounds are also mentioned in the Ti-B phase diagram: the orthorhombic TiB characterized since 1954 [19] and an intermediate compound more recently revealed: $\mathrm{Ti}_{3} \mathrm{~B}_{4}[20-21]$. 
The present paper is intended to check the formation of these compounds by chemical vapor deposition and to compare the composition of the phases deposited with the predictions of the calculation at thermodynamic equilibrium.

\section{2-Experimental}

The atmospheric pressure experimental arrangement consists of a cold wall reactor made of a quartz tube disposed vertically (Inner diameter $28 \mathrm{~mm}$ ), a gas distribution system, a heating system and a primary vacuum rotary pump. A liquid nitrogen cooled trap attached to the reactor exhaust allows unreacted precursors and by-products of the deposition reaction to condense. In order to prevent buoyancy-driven flow recirculations the hydrogen carrier gas flowed from the bottom of the reactor towards the downfacing deposition surface of the substrate. The initial gas phase was composed of $\mathrm{TiCl}_{4}$ $\mathrm{BCl}_{3}-\mathrm{H}_{2}$. The hydrogen as well as the high boron trichloride flow rates were controlled and regulated by means of mass-flowmeters. The $\mathrm{BCl}_{3}$ flow rates lower than $100 \mathrm{~cm}^{3} \cdot \mathrm{h}^{-1}$ were regulated by a special device. For that purpose a volumeter equipped with a float made of plastic and provided with an $\mathrm{Hg}$ ring was filled with $100 \mathrm{~cm}^{3}$ of boron trichloride and its flow during the experiment was regulated by a needle-valve. The hydrogen gas was first purified by permeation through a palladium alloy membrane. The $\mathrm{TiCl}_{4}$ partial pressure was controlled by the dew point method. In such a device, the partial pressure of $\mathrm{TiCl}_{4}$ is imposed by the regulated temperature of a column through which flows the gaseous mixture composed of the carrier gas (hydrogen) previously charged with $\mathrm{TiCl}_{4}$ vapor in an evaporator vessel. As the temperature of the column is lower than that of the evaporator, excess $\mathrm{TiCl}_{4}$ condenses on the wall of the column, leading to the saturation of the carrier gas. The temperature of the column can be set to a value in the range -10 to $15^{\circ} \mathrm{C}$, that allows $\mathrm{TiCl}_{4}$ flow rates of 50 to $240 \mathrm{~cm}^{3} \cdot \mathrm{h}^{-1}$ for a hydrogen flow rate of $301 . \mathrm{h}^{-1}$, as confirmed by a preliminary calibration.

The substrates (diameter $16 \mathrm{~mm}, 0.3 \mathrm{~mm}$ thick) were composed either of pure molybdenum or molybdenum coated with $\mathrm{TiC}$ as a diffusion barrier. The deposition surface was polished down to $1 \mu \mathrm{m}$ diamond grain size, sonicated and rinsed with freon. The temperature of the substrate which was inductively heated to $1473 \mathrm{~K}$ by a RF coil (250 kHz generator) was measured by an optical pyrometer $(0.65 \mu \mathrm{m})$. The measurements were corrected for the surface emissivity and for absorption through the prism and windows. The CVD system loaded with the substrate was evacuated for $8 \mathrm{~h}$ and purged with hydrogen for $30 \mathrm{~min}(30 \mathrm{l.h}-1)$ at the beginning of each experiment. At the end, the temperature of the substrate was decreased regularly and the hydrogen flow rate was maintained until the whole device had reached room temperature.

The elemental chemical composition of the deposits was measured by electron probe microanalysis with wavelength dispersive spectroscopy (EPMA-WDS). The nature of the crystalline phases was determined by X-ray diffraction analysis (XRD) on the surface of the samples.

\section{3-Results and discussion}

Two sets of experiments were carried out at $1473 \mathrm{~K}$ and atmospheric pressure: one for $\mathrm{X}\left(\mathrm{TiCl}_{4}\right)=1.710^{-3}$ and various $\mathrm{X}\left(\mathrm{BCl}_{3}\right)($ table 1$)$, the other for $\mathrm{X}\left(\mathrm{BCl}_{3}\right)=1.010^{-4}$ and various $\mathrm{X}\left(\mathrm{TiCl}_{4}\right)$ (table 2$)$.

$-\mathrm{X}\left(\mathrm{TiCl}_{4}\right) \equiv 1.710^{-3}$

Five deposits were carried out on molybdenum substrate for $\mathrm{X}\left(\mathrm{BCl}_{3}\right)$ ranging from 
$1.010^{-4}$ to $5.5310^{-3}$ (samples $1-5$, table 1). The variation of the deposition rate, plotted in figure 1, reveals the expected decrease of the deposition rate when $\mathrm{X}\left(\mathrm{BCl}_{3}\right)$ decreases. The XRD characterization only revealed the $\mathrm{TiB}_{2}$ phase in sample 1 and 2 though a composition equivalent to $\mathrm{TiB}_{2}+\mathrm{B}$ was found from EPMA-WDS, which suggests the presence of amorphous boron in the deposit. $\mathrm{TiB}_{2}$ was also found as the main component from XRD characterization in sample 3, but weak diffraction lines corresponding to $\mathrm{TiB}$ were also detected. XRD and EPMA-WDS both provided evidence of TiB deposits for samples 4 and 5. Nevertheless weak diffraction lines corresponding to $\mathrm{Mo}, \mathrm{Mo}_{2} \mathrm{~B}$ and $\mathrm{MoB}$ were also detected in these samples on account of the lower thickness of the deposits.

Due to the high solubility of molybdenum both in $\mathrm{TiB}_{2}\left((\mathrm{Ti}, \mathrm{Mo}) \mathrm{B}_{2}, \mathrm{C} 32\right.$ structure type) and in $\mathrm{TiB}((\mathrm{Ti}, \mathrm{Mo}) \mathrm{B}, \mathrm{FeB}$ structure type) [22] which gives rise to the interlayers observed by XRD, a diffusion barrier made of a 10 to $15 \mu \mathrm{m}$ thick titanium carbide was deposited prior to the Ti-B deposits. As a matter of fact, almost no interdiffusion is observed between $\mathrm{TiB}$ or $\mathrm{TiB}_{2}$ and $\mathrm{TiC}_{\mathrm{x}}$ [23-24]. Samples 6 and 7 which were deposited on $\mathrm{TiC}$ under experimental conditions similar to respectively samples 4 and 5 , are composed of pure TiB. The diffraction pattern of sample 6 , presented in figure 2 , reveals only $\mathrm{TiB}$ diffraction lines though additional lines corresponding to $\mathrm{TiC}$ are present for sample 7 (lower thickness).

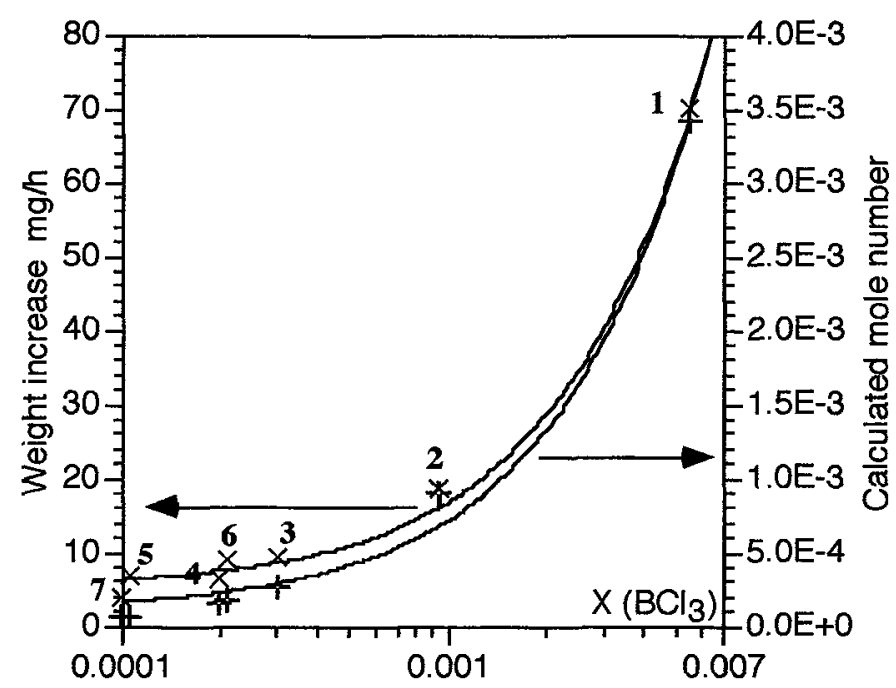

Figure 1: Comparison between the weight increase of the samples (x) and the calculated mole number of the condensed phases $(+)$ plotted as a function of the initial molar fraction of $\mathrm{BCl}_{3} . \mathrm{X}\left(\mathrm{TiCl}_{4}\right)=1.710^{-3}, \mathrm{P}=1 \mathrm{~atm}, \mathrm{~T}=1473 \mathrm{~K}$ (experiments), $\mathrm{T}=1500 \mathrm{~K}$ (calculation, without $\mathrm{Ti}_{3} \mathrm{~B}_{4}$ ).

Figure 2: TiB diffraction pattern of sample $6(\mathrm{Cu})$

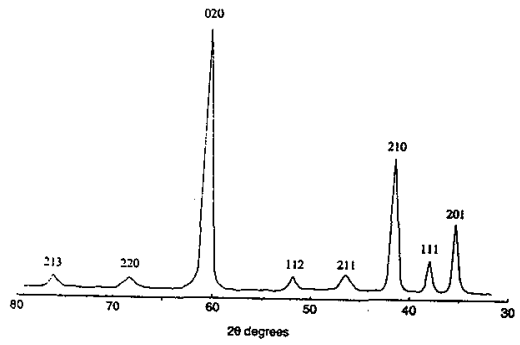


Table 1: Weight increase of the samples, and results of the thermodynamic calculation as a function of the molar fraction of $\mathrm{BCl}_{3}$ in the initial gas phase. $\mathrm{X}\left(\mathrm{TiCl}_{4}\right)=1.710^{-3}$, $\mathrm{P}=1 \mathrm{~atm}, \mathrm{~T}=1473 \mathrm{~K}$ (experiments), $\mathrm{T}=1500 \mathrm{~K}$ (calculation, without $\mathrm{Ti}_{3} \mathrm{~B}_{4}$ ).

\begin{tabular}{|c|c|c|c|c|c|}
\hline Sample & $\mathrm{X}\left(\mathrm{BCl}_{3}\right)$ & $\begin{array}{c}\text { Weight } \\
\text { increase mg }\end{array}$ & $\begin{array}{l}\text { Deposition } \\
\text { time min }\end{array}$ & $\begin{array}{c}\text { Deposited } \\
\text { phases } \\
\text { XRD + } \\
\text { EPMA-WDS }\end{array}$ & $\begin{array}{c}\text { Calculated } \\
\text { condensed } \\
\text { phase }\end{array}$ \\
\hline 1 & $5.53 \mathrm{E}-3$ & 70 & 60 & $\mathrm{TiB}_{2}+\mathrm{B}$ & $\mathrm{TiB}_{2}+\mathrm{B}$ \\
\hline 2 & $9.33 \mathrm{E}-4$ & 74 & 240 & $\mathrm{TiB}_{2}+\mathrm{B}$ & $\mathrm{TiB}$ \\
\hline 3 & $3.00 \mathrm{E}-4$ & 35 & 225 & $\mathrm{TiB}_{2}+\mathrm{TiB}$ & TiB \\
\hline 4 & $2.00 \mathrm{E}-4$ & 19 & 180 & $\mathrm{TiB}$ & $\mathrm{TiB}$ \\
\hline 5 & $1.07 \mathrm{E}-4$ & 15 & 240 & $\mathrm{TiB}$ & TiB \\
\hline 6 & $2.10 \mathrm{E}-4$ & 34 & 225 & TiB & TiB \\
\hline 7 & $1.00 \mathrm{E}-4$ & 27 & 240 & $\mathrm{TiB}$ & TiB \\
\hline
\end{tabular}

\section{$-\mathrm{X}\left(\mathrm{BCl}_{3}\right) \equiv 1.010^{-4}$}

Two complementary experiments were carried out at low $\mathrm{X}\left(\mathrm{BCl}_{3}\right)$ on molybdenum coated with TiC. The decrease of the deposition rate which is observed in figure 3 results from the modification of the phases deposited. As a matter of fact, TiB is deposited at low $\mathrm{TiCl}_{4}$ content (sample 7) though a mixture of $\mathrm{TiB}$ and $\mathrm{TiB}_{2}$ is obtained for $\mathrm{X}\left(\mathrm{TiCl}_{4}\right)$ higher than $6.010^{-3}$ (table 2). As the initial content of $\mathrm{BCl}_{3}$ is fixed for all these experiments, the deposition amount of $\mathrm{TiB}_{2}$, which requires twice as much $\mathrm{BCl}_{3}$ as for TiB, will be lower than that of TiB.

As a conclusion of the experimental section, we can say that the $\mathrm{TiB}_{2}+\mathrm{B}$ (amorphous), $\mathrm{TiB}_{2}, \mathrm{TiB}_{2}+\mathrm{TiB}$ and $\mathrm{TiB}$ domains of the Ti-B phase diagram can be deposited by CVD, but none of the experimental conditions investigated allowed the deposition of $\mathrm{Ti}_{3} \mathrm{~B}_{4}$ which was nevertheless expected as an intermediate compound between $\mathrm{TiB}$ and $\mathrm{TiB}_{2}$.

Table 2: Weight increase of the samples, and results of the thermodynamic calculation as a function of the molar fraction of $\mathrm{TiCl}_{4}$ in the initial gas phase. $\mathrm{X}\left(\mathrm{BCl}_{3}\right)=1.010^{-4}$, $\mathrm{P}=1 \mathrm{~atm}, \mathrm{~T}=1473 \mathrm{~K}$ (experiments), $\mathrm{T}=1500 \mathrm{~K}$ (calculation, without $\mathrm{Ti}_{3} \mathrm{~B}_{4}$ ).

\begin{tabular}{|c|c|c|c|c|c|}
\hline sample & $\mathrm{X}\left(\mathrm{TiCl}_{4}\right)$ & $\begin{array}{c}\text { Weight } \\
\text { increase } \\
\mathrm{mg}\end{array}$ & $\begin{array}{l}\text { Deposition } \\
\text { time min }\end{array}$ & $\begin{array}{c}\text { Deposited } \\
\text { phases } \\
\text { XRD + } \\
\text { EPMA-WDS }\end{array}$ & $\begin{array}{l}\text { Calculated } \\
\text { condensed } \\
\text { phase }\end{array}$ \\
\hline 5 & $1.70 \mathrm{E}-3$ & 15 & 240 & TiB & $\mathrm{TiB}$ \\
\hline 7 & $1.70 \mathrm{E}-3$ & 27 & 240 & $\mathrm{TiB}$ & $\mathrm{TiB}$ \\
\hline 8 & $6.00 \mathrm{E}-3$ & 9 & 210 & $\mathrm{TiB}_{2}+\mathrm{TiB}$ & $\mathrm{TiB}$ \\
\hline 9 & $1.50 \mathrm{E}-2$ & 7 & 180 & $\mathrm{TiB}_{2}+\mathrm{TiB}$ & $\mathrm{TiB}$ \\
\hline
\end{tabular}




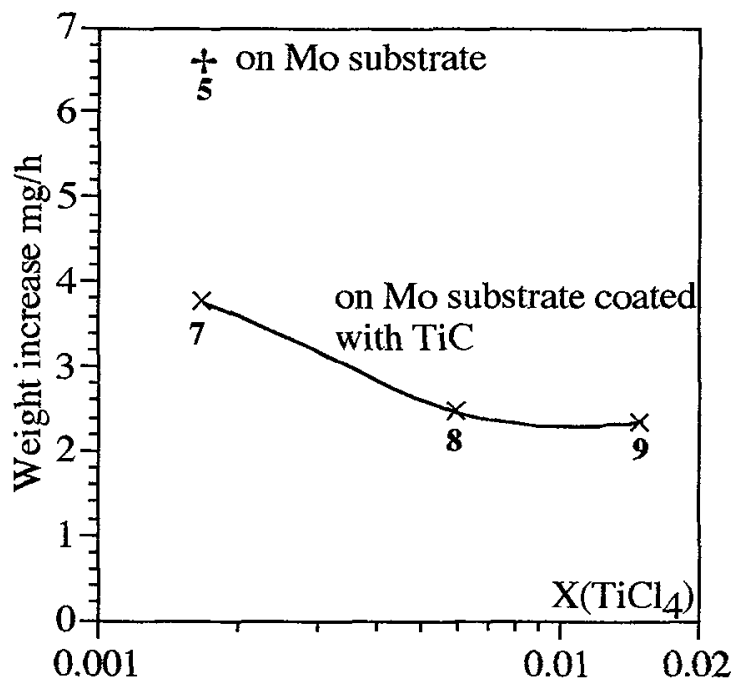

Figure 3: Variation of the weight increase of the samples plotted as a function of the initial molar fraction of $\mathrm{TiCl}_{4} . \mathrm{X}\left(\mathrm{BCl}_{3}\right)=1.010^{-4}, \mathrm{P}=1 \mathrm{~atm}, \mathrm{~T}=1473 \mathrm{~K}$.

\section{4-Thermodynamic analysis}

Several thermodynamic analyses of the chemical vapor deposition of $\mathrm{TiB}_{2}$ were already performed by other authors. After a first attempt to look at the thermodynamic calculation of the CVD of $\mathrm{TiB}_{2}$ [13] a more extensive calculation [25] presented the deposition diagrams of $\mathrm{TiB}_{2}$ and $\mathrm{TiB}_{2}+\mathrm{Ti}$ as a function of the $\mathrm{B} /(\mathrm{B}+\mathrm{Ti})$ and $\mathrm{Cl} /(\mathrm{Cl}+\mathrm{H})$ fractions in the reactant gas. This calculation did not include $\mathrm{Ti}_{3} \mathrm{~B}_{4}$ and the deposition of either $\mathrm{Ti}(\mathrm{S})$ or $\mathrm{TiB}$ was not predicted under any of the CVD conditions investigated. More recently [26], the various phase fields accessible by CVD were calculated and presented in the quaternary phase diagram Ti-B-H-Cl. Like in the previous case, the $\mathrm{Ti}_{3} \mathrm{~B}_{4}$ solid phase was not considered and the authors concluded, according to the extremely narrow deposition domain of $\mathrm{TiB}$, that this compound can be ignored for practical CVD purposes. The influence of the substrate has also been taken into account in thermodynamic calculation [27] though the list of the condensed or gaseous species considered in the calculation were not given. In order to complete such a presentation we have also to mention the influence of the mass transport phenomena in the gas phase on the shift of the boundaries of the CVD deposition diagram calculated at thermodynamic equilibrium [28].

In the present paper the deposition diagram corresponding to the formation of the condensed phases $\mathrm{TiB}_{2}, \mathrm{TiB}, \mathrm{Ti}_{3} \mathrm{~B}_{4}, \mathrm{Ti}$ and $\mathrm{B}$ is calculated from an initial gas mixture composed of $\mathrm{TiCl}_{4}-\mathrm{BCl}_{3}-\mathrm{H}_{2}$. The deposition fields are presented in a logarithmic diagram of the precursors $\mathrm{TiCl}_{4}$ and $\mathrm{BCl}_{3}$, the amount of hydrogen being calculated from the equation: $\mathrm{X}\left(\mathrm{TiCl}_{4}\right)+\mathrm{X}\left(\mathrm{BCl}_{3}\right)+\mathrm{X}\left(\mathrm{H}_{2}\right)=1$. In order to perform the thermodynamic calculations, the SOLGASMIX program [29] which minimises the Gibbs free energy of the whole chemical system was used. Such a calculation requires the thermodynamic data corresponding to all the species that may form at equilibrium. The thermodynamic values for the condensed species are taken from the most recent assessment of the Ti-B phase diagram [30]. The gaseous mixture considered in the calculation was composed of $\mathrm{H}_{2}, \mathrm{H}, \mathrm{Cl}_{2}, \mathrm{Cl}, \mathrm{BCl}, \mathrm{BCl}_{2}, \mathrm{BCl}_{3}, \mathrm{HBCl}_{2}, \mathrm{BH}, \mathrm{BH}_{2}, \mathrm{BH}_{3}$, 
$\mathrm{B}_{2} \mathrm{Cl}_{4}, \mathrm{~B}_{2} \mathrm{H}_{6}, \mathrm{HCl}, \mathrm{TiCl}_{4}, \mathrm{TiCl}_{3}, \mathrm{TiCl}_{2}, \mathrm{TiCl}$ and the corresponding thermodynamic data were taken from SGTE data bank [31]. As no thermodynamic values were available for $\mathrm{H}_{2} \mathrm{BCl}$, these were estimated according to ref. [25].

The deposition diagram calculated at $1500 \mathrm{~K}$ is presented in figure 4 together with the position of the nine experiments above described. In accordance with the Ti-B phase diagram seven solid domains are observed and two main regions can be distinguished:

- for $\mathrm{BCl}_{3} / \mathrm{TiCl}_{4}>2$ the excess of $\mathrm{BCl}_{3}$ is large enough to allow the precipitation of boron in excess and the two phased domain $\mathrm{TiB}_{2}+\mathrm{B}$ is obtained

- in the other part of the deposition diagram, the boundaries between the successive domains are not dependent on the partial pressure of $\mathrm{BCl}_{3}$ as long as $\mathrm{BCl}_{3} / \mathrm{TiCl}_{4}<0.001$. $\mathrm{BCl}_{3}$ is in that case completely decomposed and the gas equilibrium that involves the titanium subchlorides is not modified by the amount of $\mathrm{BCl}_{3}$. As a consequence, the titanium activity is only dependent on the partial pressure of $\mathrm{TiCl}_{4}$ in $\mathrm{H}_{2}$ and the boundaries are perpendicular to the $\mathrm{TiCl}_{4}$ axis. At high partial pressures of $\mathrm{TiCl}_{4}$ or $\mathrm{TiCl}_{4}$ and $\mathrm{BCl}_{3}$, titanium and boron remain dissolved in the gas phase and no solid deposits are obtained.

The comparison between the experimental and calculated compositions, shows a good accordance for sample 1 as well as for samples 5 to 7 . For samples 3 and $8 \mathrm{TiB}$ is expected though $\mathrm{TiB}_{2}+\mathrm{B}$ was deposited and for samples 2 and $9 \mathrm{Ti}_{3} \mathrm{~B}_{4}$ is expected though $\mathrm{TiB}$ was experimentally obtained.

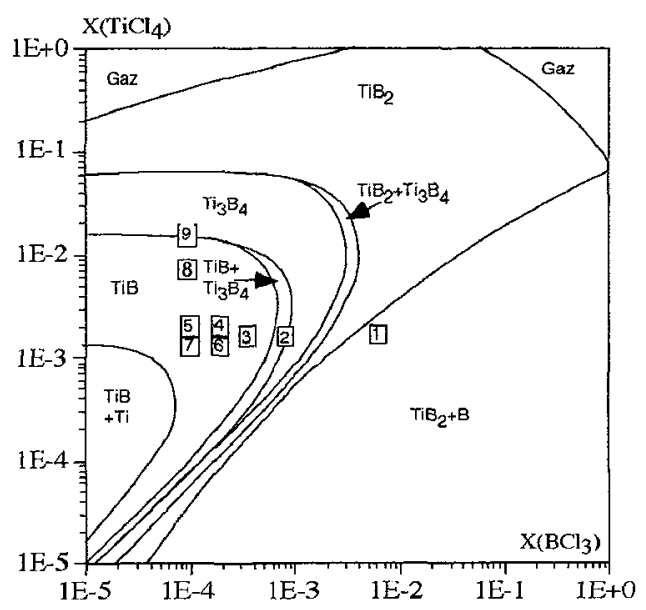

Figure 4: Calculated deposition diagram at $1500 \mathrm{~K}$ and $1 \mathrm{~atm}$, including $\mathrm{Ti}_{3} \mathrm{~B}_{4}$. $\mathrm{X}\left(\mathrm{TiCl}_{4}\right)+\mathrm{X}\left(\mathrm{BCl}_{3}\right)+\mathrm{X}\left(\mathrm{H}_{2}\right)=1$

The absence of experimental evidence for the deposition of $\mathrm{Ti}_{3} \mathrm{~B}_{4}$ may result from an extremely narrow deposition domain, which is nevertheless not predicted from a thermodynamic point of view, or from the metastability of that compound. The same thermodynamic calculation was thus carried out without $\mathrm{Ti}_{3} \mathrm{~B}_{4}$. The resulting deposition diagram is presented in figure 5. The calculated composition of the condensed phases compared with the experimental results (table 1,2) shows that the same samples as in the calculation including $\mathrm{Ti}_{3} \mathrm{~B}_{4}$ are in agreement. The shift of the experimental compositions with respect to those calculated can be interpreted as the result of a lower content of both $\mathrm{X}\left(\mathrm{TiCl}_{4}\right)$ and $\mathrm{X}\left(\mathrm{BCl}_{3}\right)$ at the interface gas-substrate than in the initial gas mixture. 


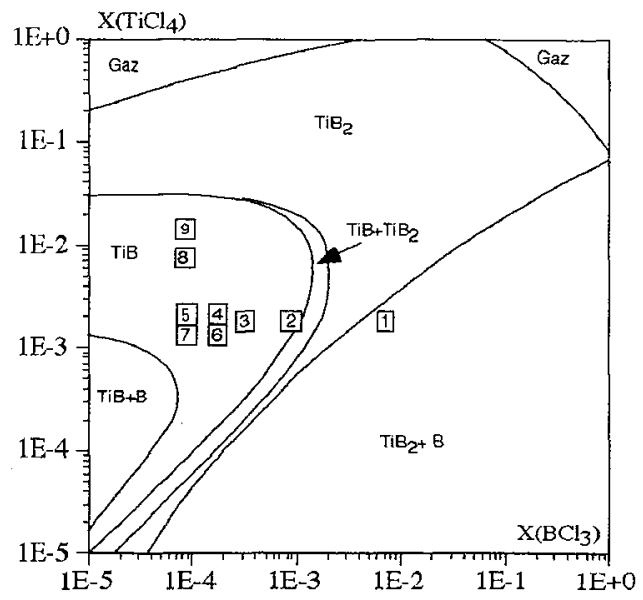

Figure 5: Calculated deposition diagram at $1500 \mathrm{~K}$ and $1 \mathrm{~atm}$, without $\mathrm{Ti}_{3} \mathrm{~B}_{4}$. $\mathrm{X}\left(\mathrm{TiCl}_{4}\right)+\mathrm{X}\left(\mathrm{BCl}_{3}\right)+\mathrm{X}\left(\mathrm{H}_{2}\right)=1$

\section{5-Hardness of $\mathbf{T i B}_{2}$ measured by ultra low load indentation}

Ultra low load indentation tests were performed on $\mathrm{TiB}_{2}$ samples (Nanoindenter II, nanoinstrument). The indentation sequence was composed of a first cycle with a loading rate of $200 \mu \mathrm{N} / \mathrm{s}$ applied to a load of $2 \mathrm{mN}$, hold for $10 \mathrm{~s}$ and followed by an unloading rate equal to the loading rate and performed to a load of $20 \%$ of the last maximum. A second cycle with a loading rate of $600 \mu \mathrm{N} / \mathrm{s}$ applied to a load of $6 \mathrm{mN}$, hold $10 \mathrm{~s}$ and a constant unloading of $250 \mu \mathrm{N} / \mathrm{s}$. This sequence was used for 10 indentations on the sample.

The modulus thus deduced from the slopes of the tangents in figure $6(436.02 \pm 14.55$ GPa $1^{\text {st }}$ cycle, $532.89 \pm 11.98 \mathrm{GPa}$ second cycle) are in good accordance with literature. In contrast, the film is very hard with a hardness value higher than that encountered in literature (30-35 GPa). The enhancement of these values may be induced by the metallographic preparation of the surface. The difference between the hardness calculated from the first cycle $(36.61 \pm 1.45 \mathrm{GPa})$ and the second one $(45.94 \pm 1.80 \mathrm{GPa})$ may result from the effect of rounding tip: the influence of the geometry of the round part of the tip is still important at very low load.

The behavior of $\mathrm{TiB}_{2}$ is rather typical of ceramics in terms of elastic contribution in the indentation process.

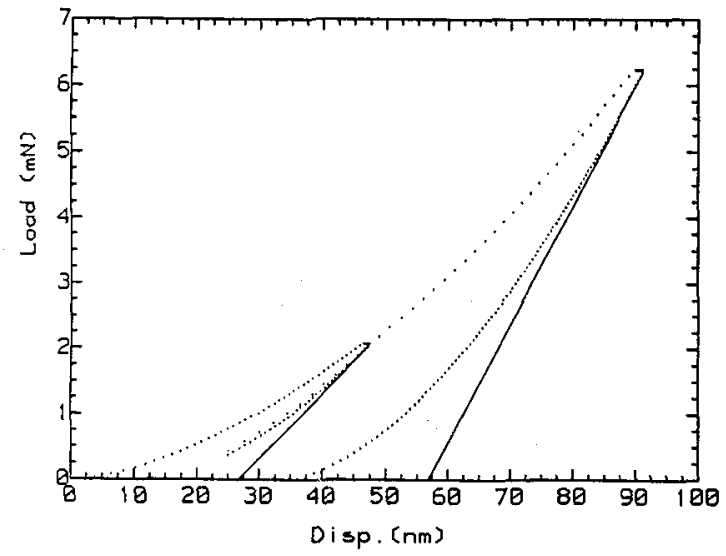

Figure 6: Load-displacement curve for $\mathrm{TiB}_{2}$ 


\section{Acknowledgement}

The authors gratefully acknowledge Dr M.E. O'Hern from Nano Instruments Inc. Knoxville USA for the nanohardness measurements.

\section{6-Bibliography}

[1] C.S.Choi, G.A.Ruggles, A.S.Shah, G.C.Xing, C.M.Osburn and J.D.Hunn, J.Electrochem.Soc. 138 (1991) 3062.

[2] H.Itoh, J.Cryst.Growth 57 (1982) 456.

[3] J.R.Shappirio, R.A.Finnegan, R.A.Lux, J.Kwiatkowski, H.Kattelus and M.A.Nicolet, J.Vac.Sci.Technol.,A 3 (1985) 2255.

[4] P.Peshev, Z.Zakhariev and K.Petrov, J.Less-Common Met. 67 (1979) 351 .

[5] C.Feldman, F.G.Satkiewicz and G.Jones, J.Less-Common Met. 79 (1981) 221.

[6] J.Elders, P.A.Quist, B.Rooswijk, J.D.W.Van Voorst and J.Van Nieuwkoop, Surf.Coat.Technol. 45 (1991) 105.

[7] K.Sugiyama, S.Iwakoshi, S.Motojima and Y.Takahashi, J.Cryst.Growth 43 (1978) 533.

[8] M.Mukaida, T.Goto and T.Hirai, J.Mater.Sci. 25(1990) 1069.

[9] T.M.Besmann and K.E.Spear, J.Cryst.Growth 31 (1975) 60.

[10] R.E.Gannon, R.C.Folweiler and T.Vasilos, J.Am.Ceram.Soc. 46 (1963) 496.

[11] T.Takahashi and H.Kamiya, J.Cryst.Growth 26 (1974) 203.

[12] G.Blandenet, Y.Lagarde, J.P.Morlevat and G.Uny, Proc. of the VI Intern. Conf. on CVD, Atlanta USA, Donaghey L.F., Rai-Choudhury P., Tauber R.N. (Eds), (1977) 330.

[13] P.Peshev and T.Niemyski, J.Less-Common Met. 10 (1965) 133.

[14] F.Zeman, J.Stamberger, J.Mayerhofer and A.Kulmburg, Proc. of the VIII Intern. Conf. on CVD, Paris FRANCE, Wahl G., Blocher J.M., Vuillard G.E. (Eds), (1981) 628.

[15] M.Mukaida, T.Goto and T.Hirai, J.Mater.Sci. 26 (1991) 6613.

[16] H.O.Pierson and E.Randich, Thin Solid Films 54 (1978) 119.

[17] H.O.Pierson and E.Randich, Proc. of the VI Intern. Conf. on CVD, Atlanta USA, Donaghey L.F., Rai-Choudhury P., Tauber R.N. (Eds), (1977) 304.

[18] H.J.LVan der valk and J.H.F.Grondel, Solid State Ionics 16 (1985) 99.

[19] B.F.Decker and J.S.Kasper, Acta Cryst. 7 (1954) 77.

[20] R.G.Fenish, Trans.Met.Soc.AIME 236 (1966) 804.

[21] K.E.Spear, P.Mc Dowell and F.Mc Mahon, J.Am.Ceram.Soc. 69 (1986) C4.

[22] AWittmann, H.Nowotny and H.Boller, Monatsch.Chem. (1959) 608.

[23] A.N.Piljankevich, V.N.Razorenov, G.L.Zhunkovski and L.V.Strashinskaya, VI Intern.Pulvermet.Tagung, DDR, Dresden 1977, Vorabdruck 2 (1977) 44-1.

[24] E.Rudy and ST.Windisch, AFML-TR-65-2 (1966) .

[25] T.M.Besmann and K.E.Spear, J.Electrochem.Soc. 124 (1977) 786.

[26] E.Randich and M.Gerlach, Thin Solid Films 75 (1981) 271.

[27] C.S.Choi, G.A.Ruggles, C.M.Osburn and G.C.Xing, J.Electrochem.Soc. 138 (1991) 3053.

[28] D.E.Rosner and J.Collins, Proc. of the XI Intern. Conf. on CVD, Seattle USA, Cullen G.W., Spear K.E. (Eds), (1990) 49.

[29] I.Kimura, N.Hotta, M.Ishii and M.Tanaka, J.Mater.Sci. 26 (1991) 258.

[30] J.L.Murray, P.K.Liao and K.E.Spear, Bulletin of Alloy Phase Diagrams 7 (1986) 550.

[31] SGTE: "Scientific Group Thermodata Europe" data base, update 1987. 